\title{
Prospective comparative trial to define the optimum time for insemination during stimulated intrauterine insemination cycles
}

Original Article

\author{
Hany A Elkallaf
}

Departments of Obstetrics and Gynecology, Faculty of Medicine, Benha University

\begin{abstract}
Objectives: To determine the clinical pregnancy rate (CPR) of women who underwent clomiphene citrate (CC) and human menopausal gonadotropin ovarian stimulation (OS) followed by intrauterine insemination (IUI) at varied times after hCG ovulation triggering and to determine the appropriate IUI timing.

Patients and Methods: 152 women with primary infertility secondary to male subfertility were randomly allocated into groups (I-IV) according to timing of IUI at 34-35, 35-36, 36-37, and 37-38hr after ovulation triggering. OS consisted of 5-days oral CC $100 \mathrm{mg}$ once daily since day-3 of the menstrual cycle followed by daily injection of human menopausal gonadotropin $150 \mathrm{IU}$ since day-8 until hCG injection. Ovulation was monitored using TVU for evident ovulation with a dominant follicle size $>18 \mathrm{~mm}$. IUI was repeated for three cycles and women were evaluated for clinical pregnancy rate (CPR) and abortion and multiple pregnancy rates were recorded.

Results: 44 women had clinical pregnancy for a total CPR of $28.9 \%$. CPR \% /patient was $15.8 \%, 34.2 \%, 42.1 \%$ and $23.7 \%$ and CPR\%/cycle was 6, 14, 20 and 11 in the four groups, respectively with significant differences in favor of group III. Three women had ectopic and six women had multiple pregnancy and five women had abortion. Statistical analyses defined high number of performed IUI cycles as significantly negative, while longer time till IUI after hCG injection as significantly positive predictor for trial success. Kaplan-Meier regression analysis defined $37 \mathrm{hr}$ (95\% CI: 36.5-37.5) after hCG injection as the appropriate time to get the best chance for IUI success.

Conclusion: IUI after CC $+\mathrm{GN}$ ovarian stimulation is an appropriate policy for infertile couples secondary to male subfertility. Total motile sperm count threshold at $\geq 5$ million gives acceptable outcome. Semen injection at $37 \mathrm{hr}$ after hCG ovulation triggering gives the highest CPR.
\end{abstract}

Key Words: Clinical pregnancy rate , Combined ovarian stimulation, Intrauterine insemination, Timing of semen injection, .

Received: 12 June 2018, Accepted: 18 August 2018

Corresponding Author: Hany A Elkallaf, Departments of Obstetrics and Gynecology, Faculty of Medicine, Benha University, E-mail: kaainih@yahoo.com

ISSN: 2090-7265, November 2018, Vol.8, No. 4

\section{INTRODUCTION}

The clinical pregnancy rate (CPR) of the frequently used fertility treatments for couples with male subfertility is variable. ${ }^{[1]}$ In-vitro fertilization (IVF) may be associated with higher livebirth rates than expectant management or unstimulated intrauterine insemination (IUI) $\mathrm{cycles}^{[2]}$. Letrozole is more effective than clomiphene citrate (CC) for the induction of ovulation in IUI cycles ${ }^{[3]}$. However, there is no conclusive evidence of a difference in livebirth rates between IVF and IUI + gonadotropins (GN) or between IVF and IUI $+\mathrm{CC}^{[2]}$. Moreover, IUI clinical pregnancy rates were significantly higher by antagonist protocol than by $\mathrm{CC}^{[4]}$.

Intrauterine insemination involves the direct intrauterine placement of sperm at time of ovulation in natural menstrual cycle or following ovarian stimulation $(\mathrm{OS})^{[5]}$. IUI is especially relevant for couples with moderate male factor infertility ${ }^{[6]}$ as it increases the chance for maximum number of healthy sperm to reach the site of fertilization and efficiently performed IUI gives pregnancy rates equally good to $\mathrm{IVF}^{[2,7]}$. Moreover, IUI yields a higher cumulative pregnancy rate than intra-cervical insemination in both natural and stimulated cycles ${ }^{[8]}$.

Sperm parameters were intensively studied as predictors for success of IUI and the best chance of clinical pregnancy was found to occur when both motility and morphology values are above normal thresholds ${ }^{[9]}$. The effect of number of inseminations is another point of discussion as no difference in CPR was previously reported with two inseminations compared to one insemination ${ }^{[10]}$ and the use of double IUI was found to be disappointing as it requires a second appointment and insemination, thus making the treatment more complex and expensive, without a 
clear evidence of a benefit ${ }^{[11]}$. Time lag between semen processing and insemination is an additional factor for success of IUI trial. The time interval from the end of sperm processing to IUI was found to be a significant factor influencing the $\mathrm{CPR}^{[12]}$.

Furthermore, time of semen injection in relation to time of ovulation triggered by human chroionic gonadotrophin (hCG) administration is still a matter of debit as it was documented to be the most important subject which can determine the success of IUI ${ }^{[13]}$. Wang et al. ${ }^{[14]}$ found that pregnancy rates were similar when IUI was performed at either 24 or $36 \mathrm{hr}$ after hCG injection in ovarian stimulated cycles and Guzick ${ }^{[15]}$ compared IUI at 33 vs. 39 hours after hCG administration and concluded that one well-timed insemination within several hours of ovulation represents a reasonable balance between efficacy and cost.

\section{Objectives}

The current study aimed to determine CPR of women underwent $\mathrm{CC}$ ovarian stimulation followed by IUI at varied times ranging between 34 and $38 \mathrm{hr}$ after hCG injection so as to determine the appropriate timing for IUI after ovulation being triggered.

\section{Design}

Prospective comparative trial

\section{Setting}

Tertiary referral hospital, KSA

\section{PATIENTS AND METHODS}

Inclusion criteria in the current study included primary infertility for more than two years, secondary to male factor and women who failed to conceive unaided or with repeated IUI cycles. The study protocol was approved by the Local Ethical Committee. All couples were eligible for evaluation for inclusion and exclusion criteria. Exclusion criteria for male partner included presence of varicocele of grade more than 2 as judged by scrotal ultrasound, obstructive lesions hampering giving seminal sample for examination and processing, hormonal disorders, and males have processed total motile sperm count (PTMS) of $<5$ million $^{[16]}$, or presence of infection. Women with endocrinal disorders, infertility for causes other than male factor and uterine abnormalities were excluded. Couples had infertility for less than two years or secondary to immunological causes or infrequent intercourse were also excluded.

Preliminary evaluation included clinical examination and transvaginal ultrasonography and estimation of baseline serum levels of FSH, LH, E2 and prolactin. Males were referred to Andrology Clinic for evaluation of exclusion criteria. Enrolled couples were randomly, using sealed envelops labeled by the group title, prepared by a blinded assistant and chosen by the couples into four groups according to timing of insemination. Group I, II, III and IV included women who received insemination at 3438-37, 37-36,36-35,35-, respectively.

All women received ovarian stimulation in the form of oral CC $100 \mathrm{mg}$ once daily since day-3 of the menstrual cycle for 5 days followed by daily injection of human menopausal gonadotropin (hMG, Pergonal, Serono) 150 IU starting on day-8 until hCG administration. Ovulation was monitored and assured using TVU for evident ovulation with a dominant follicle size $>18 \mathrm{~mm}$. For males, semen was obtained 3-days abstinence and sperms were prepared according to Density Gradient Sperm Wash Method and processed after tracking of the dominant follicles ${ }^{[17]}$ for the duration assigned for each group. IUI was repeated for three cycles and women were evaluated for clinical pregnancy rate (CPR) and abortion and multiple pregnancy rates were recorded.

Table 1: Patients' data recorded at time of study enrollment

\begin{tabular}{|c|c|c|c|c|c|c|}
\hline Data & & Group I & Group II & Group III & Group IV & $\mathrm{P}=$ \\
\hline Age (years) & & $28 \pm 3.2$ & $28.3 \pm 2.6$ & $28.5 \pm 3.3$ & $28.2 \pm 3.5$ & 0.917 \\
\hline \multirow[t]{2}{*}{ Duration of infertility (years) } & & $4 \pm 1.1$ & $3.8 \pm 1.2$ & $4.1 \pm 1.3$ & $4.1 \pm 1.7$ & 0.672 \\
\hline & Weight (kg) & $79.6 \pm 9$ & $79.2 \pm 9.2$ & $78.2 \pm 10.3$ & $80.2 \pm 9.9$ & 0.838 \\
\hline \multirow[t]{2}{*}{ BMI parameters } & Height $(\mathrm{cm})$ & $168.3 \pm 1.8$ & $168.2 \pm 1.7$ & $169.4 \pm 2.7$ & $168.8 \pm 2.5$ & 0.103 \\
\hline & BMI (kg/m2) & $28.1 \pm 3.1$ & $27.9 \pm 3.2$ & $27.3 \pm 3.6$ & $28.1 \pm 3.3$ & 0.656 \\
\hline \multicolumn{2}{|l|}{ Number of previous cycles } & $2 \pm 0.8$ & $2.2 \pm 0.85$ & $2.2 \pm 0.8$ & $2.3 \pm 0.8$ & 0.673 \\
\hline \multirow{4}{*}{ Baseline serum hormonal levels } & FSH (mIU/ml) & $5.88 \pm 2.3$ & $6.07 \pm 3$ & $6.24 \pm 2.7$ & $6.12 \pm 4.55$ & 0.867 \\
\hline & LH (mIU/ml) & $8.3 \pm 2.1$ & $7.9 \pm 1.5$ & $8.5 \pm 2.3$ & $8.9 \pm 3.5$ & 0.451 \\
\hline & Prolactin (ng/ml) & $27.3 \pm 22.3$ & $27.1 \pm 18.5$ & $25.1 \pm 15$ & $24.8 \pm 14.3$ & 0.328 \\
\hline & E2 (IU/ml) & $53.4 \pm 16.5$ & $58.7 \pm 18$ & $54.1 \pm 16.3$ & $60.9 \pm 16$ & 0.155 \\
\hline
\end{tabular}

Data are presented as mean \pm SD; BMI: body mass index; $p$ value indicates inter-group difference; $p<0.05$ indicates significant difference 


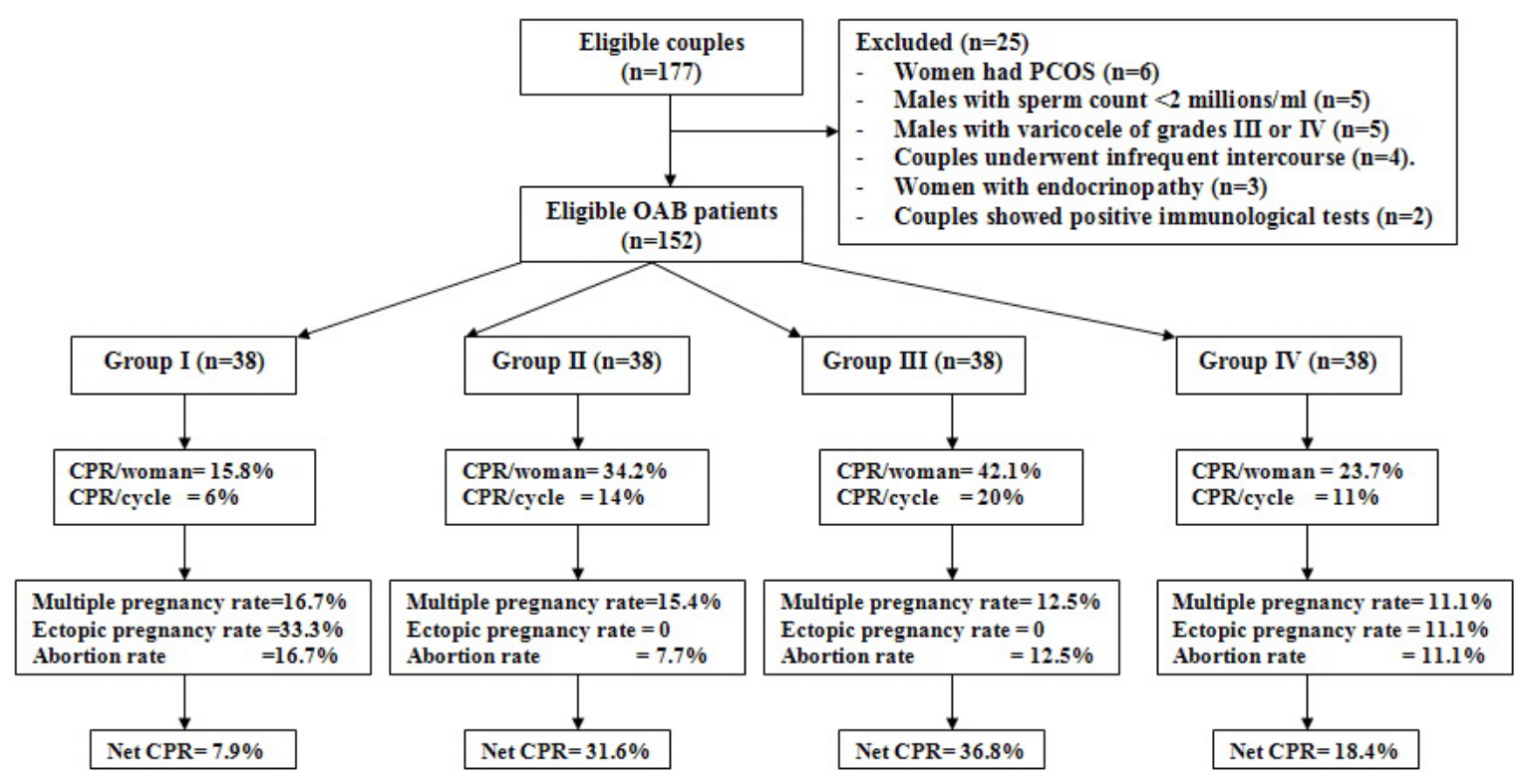

Fig. 1: Flow chart of the study

\section{Statistical analysis}

Obtained data were presented as mean $\pm \mathrm{SD}$, numbers and percentages. The results were analyzed using paired t-test and Chi-square test (X2 test). Possible relationships were investigated using Spearman's linear regression. Sensitivity and specificity of estimated parameters as predictors were evaluated using the receiver operating characteristic (ROC) curve analysis judged by the area under the curve (AUC) compared with the null hypothesis that $\mathrm{AUC}=0.05$. Statistical analysis was conducted using the IBM SPSS (Version 23, 2015) for Windows statistical package. $\mathrm{P}$ value $<0.05$ was considered statistically significant.

Table 2: Outcomes of ovarian stimulation of enrolled patients throughout the duration of the study

\begin{tabular}{|c|c|c|c|c|c|c|c|c|c|}
\hline \multicolumn{4}{|l|}{ Item } & Group & Group I & Group II & Group III & Group IV & $\mathrm{P}=$ \\
\hline \multicolumn{5}{|c|}{ Endometrial thickness (mm) } & $9.1 \pm 1.4$ & $8.3 \pm 1.6$ & $8.9 \pm 1.5$ & $9.1 \pm 1.2$ & 0.688 \\
\hline \multicolumn{4}{|c|}{ E2 (IU/ml) } & & $235 \pm 63$ & $240.7 \pm 62.1$ & $229.3 \pm 69.2$ & $227.3 \pm 69.7$ & 0.815 \\
\hline \multirow[t]{5}{*}{ Cycles } & \multicolumn{3}{|l|}{ Number } & & 99 & 90 & 77 & 81 & \\
\hline & \multicolumn{4}{|c|}{ Frequency (/patient) } & $2.6 \pm 0.5$ & $2.4 \pm 0.7$ & $2 \pm 0.7$ & $2.1 \pm 0.6$ & 0.006 \\
\hline & & & $\mathrm{P} 1$ & & & 0.021 & 0.0008 & 0.001 & \\
\hline & & & $\mathrm{P} 2$ & & & & 0.0009 & 0.029 & \\
\hline & & & P3 & & & & & 0.371 & \\
\hline \multirow[t]{6}{*}{ Follicles } & \multicolumn{9}{|l|}{ Number } \\
\hline & \multirow{4}{*}{$\begin{array}{l}\text { Frequency } \\
\text { Cycle }\end{array}$} & & Value & & 129 & 118 & 123 & 132 & \\
\hline & & & $\mathrm{P} 1$ & & $1.32 \pm 0.3$ & $1.46 \pm 0.7$ & $1.74 \pm 0.7$ & $1.76 \pm 0.7$ & 0.005 \\
\hline & & & $\mathrm{P} 2$ & & & & 0.009 & 0.008 & \\
\hline & & & P3 & & & & & 0.586 & \\
\hline & \multicolumn{4}{|c|}{ Frequency/Patients } & $3.4 \pm 0.9$ & $3.1 \pm 0.8$ & $3.2 \pm 1.1$ & $3.5 \pm 1$ & 0.688 \\
\hline
\end{tabular}

Data are presented as mean \pm SD and numbers; $p$ value indicates inter-group difference; $p<0.05$ indicates significant difference; P1 indicates significance versus group I, P2 indicates significance versus group II, P3 indicates significance versus group III 


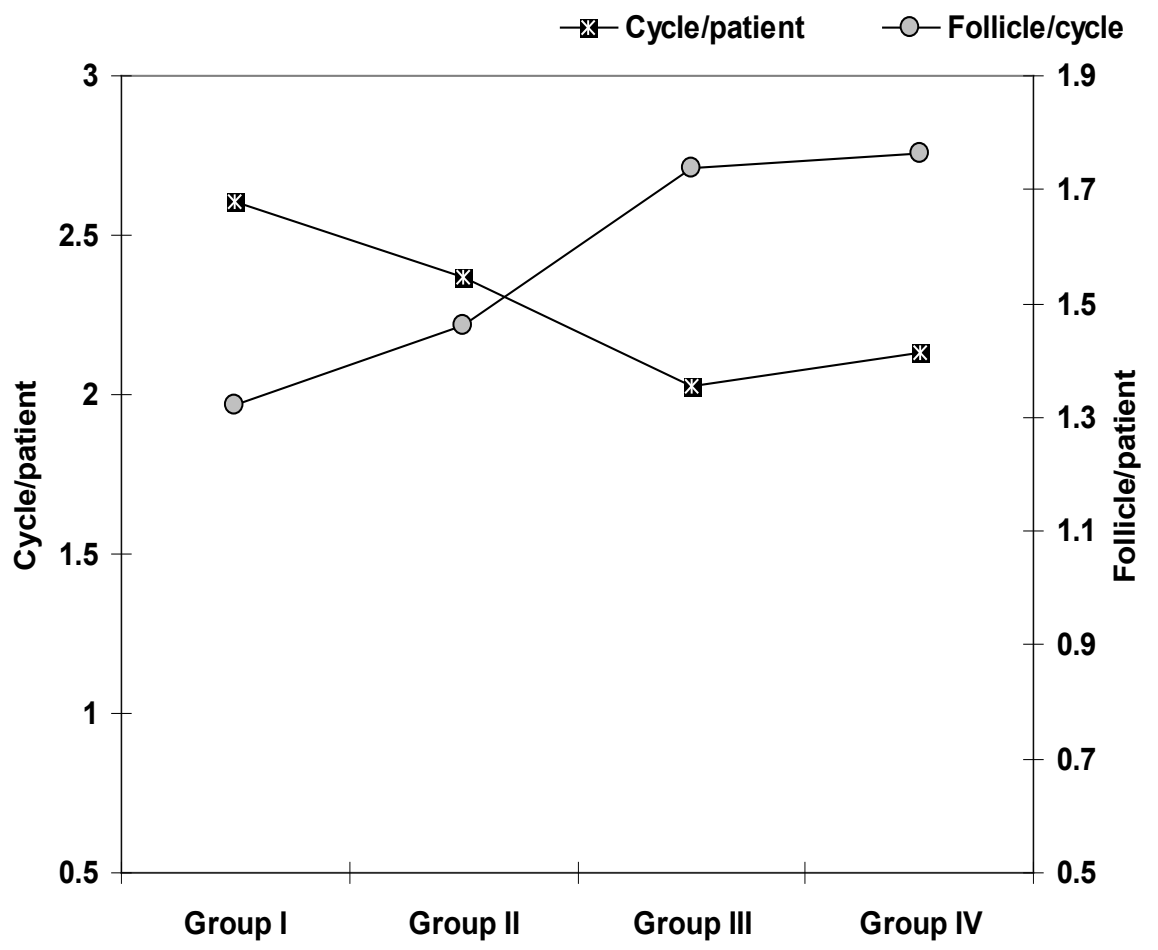

Fig. 2: The distribution of IUI cycles in relation to number of patients and mature follicles

\section{RESULTS}

The study included 177 women who were eligible for evaluation; 25 women were excluded for not fulfilling the inclusion criteria and 152 women were randomly allocated into four studied groups (Fig. 1).
Women included in the study showed non-significant differences as regards inclusion data Table (1).

Mean endometrial thickness and estimated E2 serum levels showed non-significant difference between patients of studied groups throughout duration of the

Table 3: IUI cycle outcome data of studied patients

\begin{tabular}{|c|c|c|c|c|c|c|}
\hline Item & Group & Group I & Group II & Group III & Group IV & $\mathrm{P}=$ \\
\hline \multicolumn{7}{|c|}{ Total clinical pregnancy } \\
\hline \multirow{3}{*}{$\mathrm{CPR}$} & Number of cycles & 99 & 90 & 77 & 81 & \\
\hline & CPR $(\%) /$ cycle & $6 \%$ & $14 \%$ & $20 \%$ & $11 \%$ & 0.026 \\
\hline & CPR (\%)/patient & $15.8 \%$ & $34.2 \%$ & $42.1 \%$ & $23.7 \%$ & 0.0003 \\
\hline \multicolumn{2}{|c|}{ Ectopic pregnancy rate } & $2(33.3 \%)$ & 0 & 0 & $1(11.1 \%)$ & 0.211 \\
\hline \multicolumn{2}{|c|}{ Multiple pregnancy rate } & $1(16.7 \%)$ & $2(15.4 \%)$ & $2(12.5 \%)$ & $1(11.1 \%)$ & 0.315 \\
\hline \multicolumn{2}{|l|}{ Abortion rate } & $1(16.7 \%)$ & $1(7.7 \%)$ & $2(12.5 \%)$ & $1(11.1 \%)$ & 0.723 \\
\hline \multicolumn{2}{|l|}{ Net CPR } & $3(7.9 \%)$ & $12(31.6 \%)$ & $14(36.8 \%)$ & $7(18.4 \%)$ & 0.009 \\
\hline
\end{tabular}

study. Through 347 stimulation cycles, the studied women gave 502 follicles $>18 \mathrm{~mm}$ for a frequency of 2.28 cycle/ woman and 1.45 follicle / cycle and 3.3 follicle/ woman with non-significant difference between studied women as regards the number of mature follicles/patient. The number of cycle/patient and follicle/cycle showed significant variance between the four groups. The number of cycle/patient was significantly higher in group I compared to other groups and in group II compared to groups III and IV with non-significantly higher frequency in group IV compared to group III. The number of follicle/cycle of OS was significantly higher in III and IV compared to groups I and II with non-significantly higher frequency 
Table 4: Spearman's correlation and ROC curve analysis of studied parameters for prediction of IUI trial success

\begin{tabular}{|c|c|c|c|c|c|}
\hline \multirow[t]{2}{*}{ Parameter } & \multicolumn{2}{|c|}{ Spearman's correlation } & \multicolumn{3}{|c|}{ ROC curve analysis } \\
\hline & Rho & $\mathrm{p}$ & $\operatorname{AUC}( \pm \mathrm{SE})$ & $\mathrm{p}$ & $95 \% \mathrm{CI}$ \\
\hline Age & -0.266 & 0.001 & $0.331( \pm 0.048)$ & 0.001 & $0.238-0.425$ \\
\hline Duration of infertility & 0.078 & 0.340 & $0.548( \pm 0.048)$ & 0.354 & $0.453-0.643$ \\
\hline BMI & -0.247 & 0.002 & $0.343( \pm 0.049)$ & 0.002 & $0.247-0.439$ \\
\hline Number of IUI cycles & -0.509 & 0.0008 & $0.205( \pm 0.043)$ & 0.0006 & $0.121-0.289$ \\
\hline Number of follicles & 0.224 & 0.005 & $0.637( \pm 0.054)$ & 0.008 & $0.531-0.743$ \\
\hline Endometrial thickness & 0.146 & 0.073 & $0.589( \pm 0.058)$ & 0.086 & $0.476-0.702$ \\
\hline Timing of semen injection & 0.442 & 0.0009 & $0.771( \pm 0.403)$ & 0.0004 & $0.686-0.855$ \\
\hline
\end{tabular}

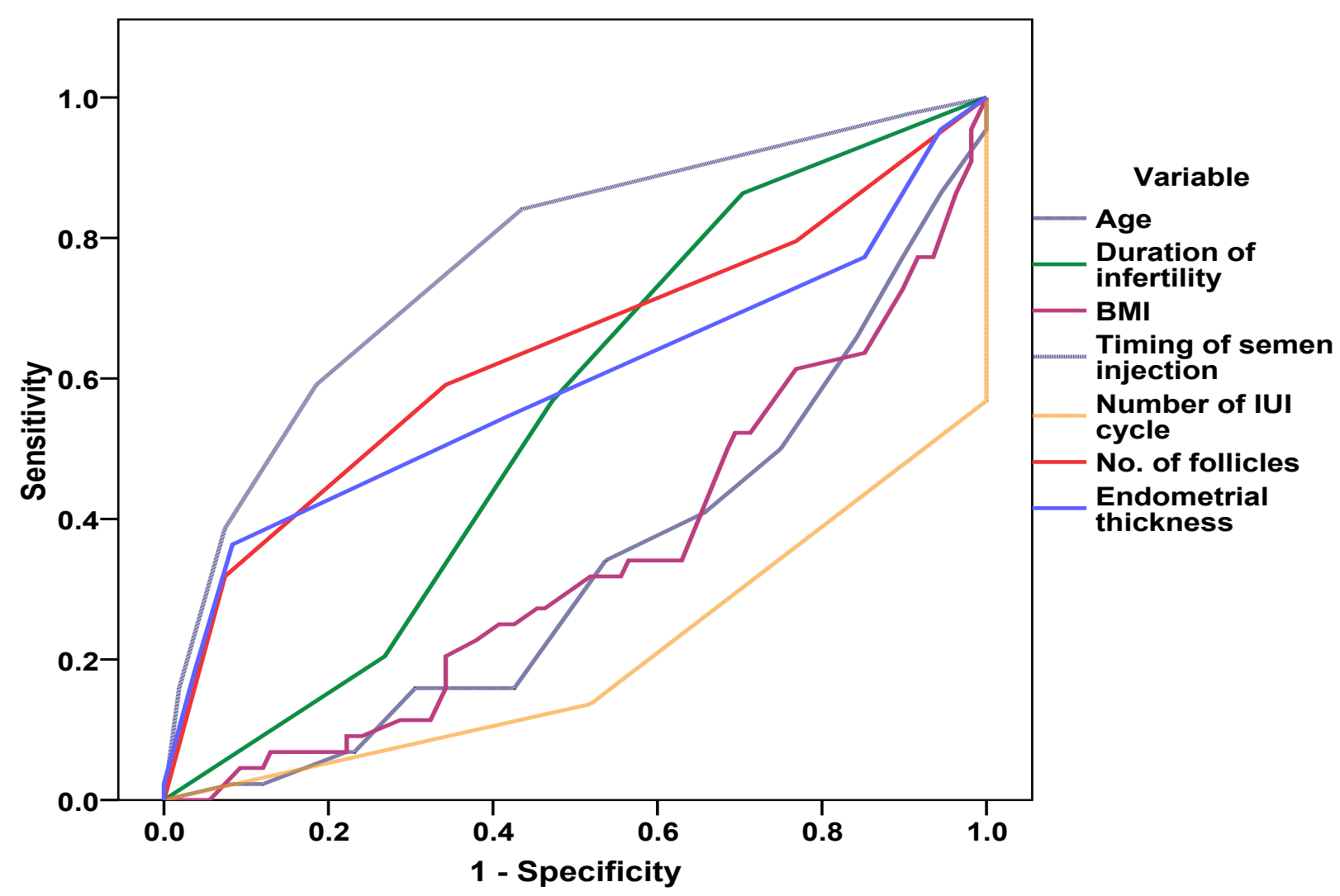

Fig. 3: ROC curve analysis for variables as predictors for IUI trial success

in groups II and IV in comparison to groups I and III, respectively, between studied groups in favor of group III Table (2), (Fig. 2).

Throughout the duration of the study, 44 women had clinical pregnancy for a total CPR of $28.9 \%$. CPR (\%) per patient was $15.8 \%, 34.2 \%, 42.1 \%$ and $23.7 \%$ in groups I-IV, respectively, with significant $(\mathrm{p}=0.0003)$ difference between groups in favor group III (Fig. 1). Moreover, CPR (\%)/cycle was 6, 14, 20 and 11 in the four groups, respectively, with significant $(p=0.026)$ difference in favor of group III. Three women had ectopic pregnancy; two in group I and one in group IV, while no woman in groups II and III had ectopic pregnancy with non-significant difference $(p=0.211)$ between groups I and IV. Six women had 
Table 5: Regression analysis of studied parameters for prediction of IUI trial success

\begin{tabular}{lccc}
\hline & Parameter & $\beta$ & $\mathrm{p}$ \\
\hline \multirow{3}{*}{ Model 1 } & Number of cycles & -0.468 & 0.0007 \\
& Timing of semen injection & 0.340 & 0.0009 \\
& Number of follicles & 0.204 & 0.001 \\
& Age & -0.134 & 0.027 \\
Model 2 & Number of cycles & -0.487 & 0.0007 \\
& Timing of semen injection & 0.359 & 0.0008 \\
& Number of follicles & 0.203 & 0.001 \\
Model 3 & Number of cycles & -0.487 & 0.0007 \\
& Timing of semen injection & 0.377 & 0.0005 \\
\hline
\end{tabular}

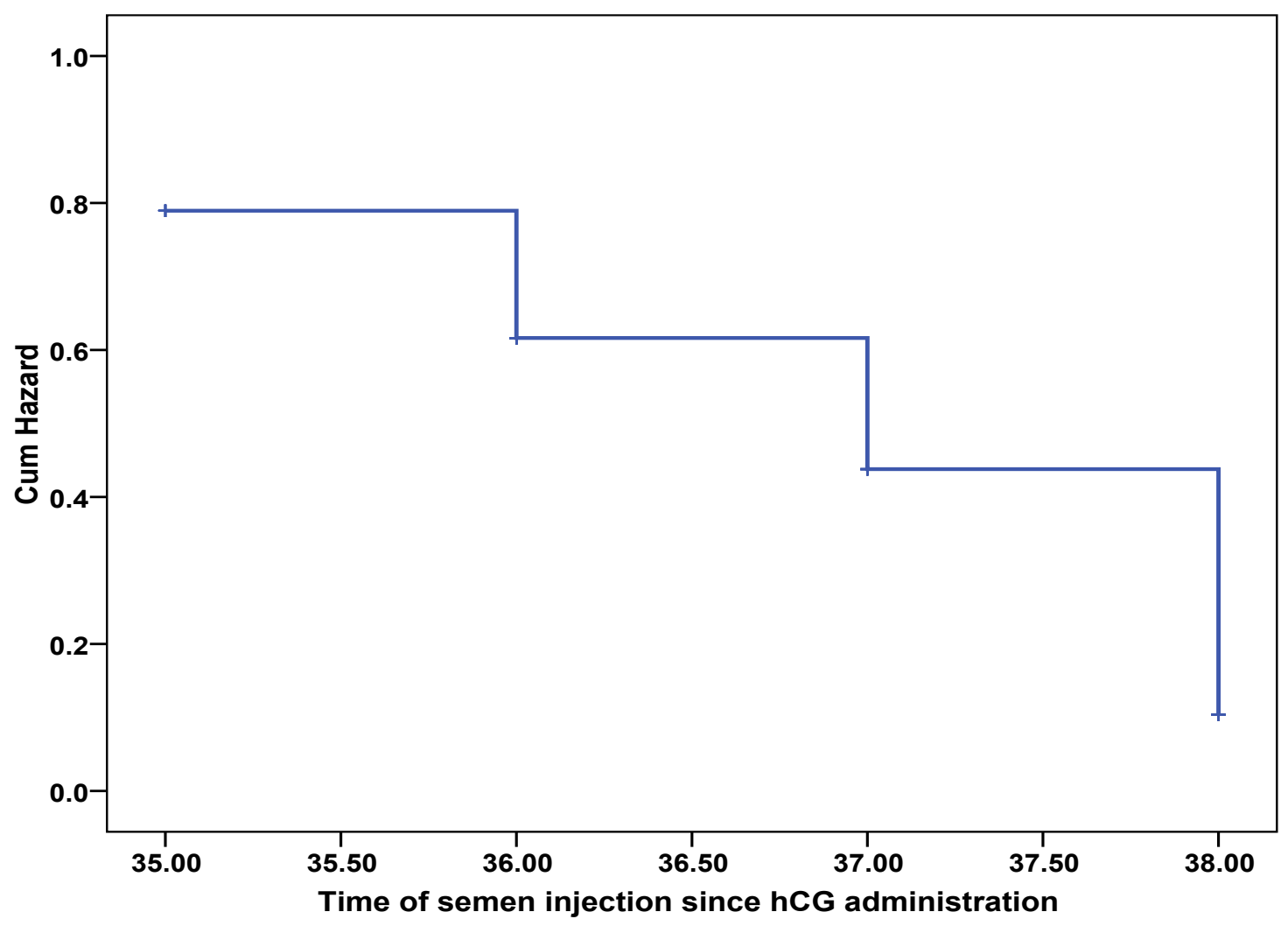

Fig. 4: Kaplan-Meier regression analysis for appropriate time of semen injection to get the best chance for IUI trial success

multiple pregnancy; one case in groups I and IV and two in each of groups II and III. Five women had abortion, two in group III and one in each of the other groups. Net pregnancy rate varied significantly among the studied groups and being the highest in groups III and II Table (3), (Fig. 1).

Spearman's correlation analysis for clinical pregnancy showed a positive significant correlation with outcome of OS protocol as evidenced by the detected positive correlation with number of follicles and endometrial thickness and with timing of semen injection, while there was negative significant correlation between age of female partner and her BMI and with number of performed IUI cycles. ROC curve analysis confirmed that timing of IUI is the best parameter for its success (Fig. 3).

Regression analysis using stepwise method defined the high number of performed IUI cycles as the persistently significant negative predictor for trial success, while the more longer time till semen injection after hCG administration as the persistently significant positive predictor for trial success.

Kaplan-Meier regression analysis for timing of semen injection defined $37 \mathrm{hr}$ (95\% CI: 36.5-37.5) after hCG as 
the appropriate time to get the best chance for IUI trial success (Fig. 4).

\section{DISCUSSION}

The current study included 152 women with primary infertility secondary to male factor and all women were gynecologically within the acceptable range for getting pregnancy. The rational of the study was to induce ovarian stimulation (OS) of a nearly normal woman for compensation of deficient male factor to augment the chance for being pregnant. Such rational coincided with that recently reported by Irani et al. ${ }^{[18]}$ who documented that couples whose total number of motile spermatozoa in the ejaculate before semen preparation is below the threshold may benefit from a superovulation.

The applied OS protocol consisted of 5-days course of daily oral CC (100 mg) since day-3 of the menstrual cycle, then daily injection of human menopausal gonadotropin(GN; $150 \mathrm{IU})$ starting on day- 8 until hCG administration. Review of literature showed contradictory outcomes concerning $\mathrm{CC}+\mathrm{GN}$ or $\mathrm{GN}$ alone where Sinha and Agrawal ${ }^{[19]}$ reported that $\mathrm{GN}$ alone appears to give better results than $\mathrm{CC}+\mathrm{GN}$, but combination is cost-effective. Moreover, Kamath et al. ${ }^{[20]}$ after a meta-analysis of published studies reported no conclusive evidence indicating that $\mathrm{CC}$ with or without GN differed from $\mathrm{GN}$ in $\mathrm{GnRH}$ agonist or antagonist protocols, but the use of CC led to a reduction in the amount of GN required and the incidence of OHSS.

On contrary to these reports and in line with the effectiveness of $\mathrm{CC}+\mathrm{GN}$ combination, Hembram et al. ${ }^{[21]}$ found that $\mathrm{CC}+\mathrm{hMG}$ is cost effective OS protocol and could be the preferred in couples with unexplained infertility undergoing IUI with no significant complications. Moreover, Banker et al. ${ }^{[22]}$ documented that GN, either alone or the combination with CC, gives a higher CPR and a lower abortion rate following IUI. Furthermore, Irani et al. ${ }^{[18]}$ concluded that the response to superovulation with CC determines each patient's total motile sperm count (TMSC) threshold required for satisfactory outcomes and couples whose TMSC is below the threshold may benefit from a superovulation with GN.

The current study included only males with $\geq 5$ million sperms with good forward motility; a limit which is coincident with the previously documented as the threshold value $^{[16]}$. In line with the applied TMSC threshold value, multiple recent studies assured the possibility of getting acceptable clinical pregnancy rate (CPR) with such limit where Madbouly et al. ${ }^{[23]}$ documented that a post-wash TMSC of $\geq 5$ million sperm is significantly associated with a high pregnancy rate. Also, Ruiter-Ligeti et al. ${ }^{[24]}$ and Hassan et al. ${ }^{[25]}$ documented that the decrease in TMSC did not negatively affect pregnancy rates. Moreover, Punjabi et al. ${ }^{[26]}$ reported that $\mathrm{CPR}$ of $13.8 \%$ versus $4.4 \%$ with $>2$ versus $<2$ million of rapid progressive spermatozoa.
The reported total CPR was $28.9 \%$ and ectopic and multiple pregnancy rates were $2 \%$ and $3.9 \%$, respectively, with an abortion rate of $3.3 \%$; so net CPR was $24.3 \%$. In line with these figures, Irani et al. ${ }^{[18]}$, Sinha and Agrawal[19], Hembram et al. ${ }^{[21]}$ and Banker et al. ${ }^{[22]}$ reported pregnancy rates of $17.8 \%, 18.9 \%, 23.3 \%$ and $14.55 \%$, respectively, with a miscarriage rate $5.43 \%{ }^{[22]}$.

The group-related CPR was $15.8 \%, 34.2 \%, 42.1 \%$ and $23.7 \%$ /patient and was $6,14,20$ and 11 /cycle in groups I-IV, respectively, with significant inter-group difference in favor of group III with significant difference between groups as regards net $\mathrm{CPR}$, being the highest in groups III and II. Statistical analyses defined timing of semen injection in relation to ovulation triggering as the significant specific and the higher number of conducted IUI cycles as the most significant sensitive parameter for success of IUI trial. Kaplan-Meier regression analysis defined $37 \mathrm{hr}$ as timing for semen injection after hCG triggering as the appropriate time to get the best chance for IUI trial success.

These results are in accordance with Jansen et al. ${ }^{[27]}$ who documented that there is no negative effect on pregnancy rate when IUI of processed sperm is delayed until the next day. Moreover, Lee et al. ${ }^{[28]}$ reported that insemination at least $36 \mathrm{~h}$ after ovulation is associated with increased pregnancy rate compared to IUI performed $\leq 36 \mathrm{~h}$ following ovulation.

Interestingly, correlation analyses for $\mathrm{CPR}$ showed a negative significant correlation with age of female partner and her BMI and with number of performed IUI cycles. Similarly, Liang et al. ${ }^{[12]}$ using Logistic multivariate analysis showed that CPR was decreased with the increased age of the women and Liu et al. ${ }^{[29]}$ found that cycle protocol and number, female age, percentage of progressively motile sperm and sperm morphology are the main factors affecting the CPR following IUI. Zhang et al. ${ }^{[30]}$ detected lower pregnancy rates with increased female age and duration of infertility. Also, Huyghe et al. ${ }^{[31]}$ documented that statistically detected significant influence of female BMI on CPR with the highest CPR was reported in women with average BMI and the lowest in obese women. Recently, $\mathrm{Na}$ et al. ${ }^{[32]}$ found the cumulative pregnancy and live birth rates tended to decrease, while abortion and ectopic pregnancy rates and cesarean delivery rate gradually increased with increased BMI and suggested that it is important to achieve a normal BMI prior to IUI.

\section{CONCLUSION}

IUI after $\mathrm{CC}+\mathrm{GN}$ ovarian stimulation is an appropriate policy for infertile couples secondary to male subfertility. Total motile sperm count threshold at $\geq 5$ million as a threshold gives acceptable outcome. Semen injection at $37 \mathrm{hr}$ after hCG ovulation triggering gives the highest CPR than other evaluated times. Wider scale studies are mandatory to establish such time cutoff point and its applicability for men with TMSC $<5$ millions. 


\section{ACKNOWLEDGEMENT}

The author thanks MISRA 2017 Scientific Organization; Biostatistics Department for Statistical Analyses and Adjustment.

\section{REFERENCES}

1. Cissen $\mathrm{M}$, Bensdorp $\mathrm{A}$, Cohlen BJ, Repping $\mathrm{S}$, de Bruin JP, van Wely M: Assisted reproductive technologies for male subfertility. Cochrane Database Syst Rev. 2016; 2:CD000360.

2. Pandian Z, Gibreel A, Bhattacharya S: In vitro fertilisation for unexplained subfertility. Cochrane Database Syst Rev. 2015; (11):CD003357.

3. Azmoodeh A, Pejman Manesh M, Akbari Asbagh F, Ghaseminejad A, Hamzehgardeshi Z: Effects of Letrozole-HMG and Clomiphene-HMG on Incidence of Luteinized Unruptured Follicle Syndrome in Infertile Women Undergoing Induction Ovulation and Intrauterine Insemination: A Randomised Trial. Glob J Health Sci. 2015; 8(4):244-52.

4. Nada AM, ElSetohy KA, Banat MM, Shaheen AF: Antagonist protocol versus clomiphene in unexplained infertility: A randomized controlled study. Taiwan J Obstet Gynecol. 2016; 55(3):326-30.

5. Bhattacharya S, Harrild K, Mollison J, Wordsworth S, Tay C, Harrold A, McQueen D, Lyall H, Johnston L, Burrage J, Grossett S, Walton H, Lynch J, Johnstone A, Kini S, Raja A, Templeton A: Clomifene citrate or unstimulated intrauterine insemination compared with expectant management for unexplained infertility: pragmatic randomized controlled trial. BMJ. 2008; 337:a716.

6. Lemmens L, Kos S, Beijer C, Brinkman JW, van der Horst FA, van den Hoven L, Kieslinger DC, van Trooyen-van Vrouwerff NJ, Wolthuis A, Hendriks JC, Wetzels AM; Semen Section of the Dutch Foundation for Quality Assessment in Medical Laboratories: Predictive value of sperm morphology and progressively motile sperm count for pregnancy outcomes in intrauterine insemination. Fertil Steril. 2016;105(6):1462-8.

7. Bahadur G, Homburg R, Al-Habib A: A New Dawn for Intrauterine Insemination: Efficient and Prudent Practice will Benefit Patients, the Fertility Industry and the Healthcare Bodies. J Obstet Gynaecol India. 2017; 67(2):79-85.

8. Kop PA, Mochtar MH, O'Brien PA, Van der Veen $\mathrm{F}$, van Wely $\mathrm{M}$ : Intrauterine insemination versus intracervical insemination in donor sperm treatment. Cochrane Database Syst Rev. 2018; 1:CD000317.

9. Butcher MJ, Janoo J, Broce M, Seybold DJ, Gantt P, Randall G: Use of Sperm Parameters to Predict Clinical Pregnancy with Intrauterine Insemination. J Reprod Med. 2016; 61(5-6):263-9.
10. Cantineau AE, Heineman MJ, Cohlen BJ: Single versus double intrauterine insemination in stimulated cycles for subfertile couples: a systematic review based on a Cochrane review. Hum Reprod. 2003; 18(5):941-6.

11. Arab-Zozani M, Nastri CO: Single versus double intrauterine insemination (IUI) for pregnancy: A systematic review and meta-analysis. Eur J Obstet Gynecol Reprod Biol. 2017; 215:75-84.

12. Liang JY, Li ZT, Yang XH, Huang ZC, Yang SF, Wang LH, Liu FH: Time interval from the end of sperm processing to artificial intrauterine in semination with husband's sperm correlates to the rate of clinical pregnancy. Zhonghua Nan Ke Xue. 2015; 21(6):532-5.

13. Ragni G, Somigliana E, Vegetti W: Timing of intrauterine insemination: where are we? Fertil Steril 2004; 82(1):25-6.

14. Wang YC, Chang YC, Chen IC, Cnien HH, Wu GJ: Comparison of timing of IUI in ovarian stimulated cycles. Arch Androl. 2006; 52(5):371-4.

15. Guzick DS: For now, one well-timed intrauterine insemination is the way to go. Fertil Steril. 2004; 82(1):30-5.

16. Merviel P, Heraud MH, Grenier N, Lourdel E, Sanguinet $\mathrm{P}$, Copin $\mathrm{H}$ : Predictive factors for pregnancy after intrauterine insemination (IUI): an analysis of 1038 cycles and a review of the literature. Fertil Steril. 2010; 93(1):79-88.

17. Akram A, Imtiaz SA, Jahan S: Effect of sperm parameters on intrauterine insemination pregnancy rate. J Coll Physicians Surg Pak. 2008; 18(6):342-6.

18. Irani M, Chow S, Keating D, Elder S, Rosenwaks Z, Palermo G: Optimizing the first-line fertility treatment. Gynecol Endocrinol. 2018 Feb 20:1-5.

19. Sinha S, Agrawal N: Gonadotropin Alone is a Better Drug for Ovarian Stimulation than in Combination with Clomiphene in Intrauterine Insemination. J Obstet Gynaecol India. 2016; 66(5):333-8.

20. Kamath MS, Maheshwari A, Bhattacharya S, Lor KY, Gibreel A: Oral medications including clomiphene citrate or aromatase inhibitors with gonadotropins for controlled ovarian stimulation in women undergoing in vitro fertilisation. Cochrane Database Syst Rev. 2017 Nov 2; 11:CD008528.

21. Hembram M, Biswas R, Jain A: A Study of Controlled Ovarian Stimulation with Clomiphene Citrate or Letrozole in Combination with Gonadotropins and IUI in Unexplained Infertility. J Hum Reprod Sci. 2017; 10(3):173-177. 
22. Banker M, Patel A, Deshmukh A, Shah S: Comparison of Effectiveness of Different Protocols Used for Controlled Ovarian Hyperstimulation in Intrauterine Insemination Cycle. J Obstet Gynaecol India. 2018 Feb;68(1):65-69.

23. Madbouly K, Isa A, Habous M, Almannie R, AbuRafea B, Binsaleh S: Postwash total motile sperm count: should it be included as a standard male infertility work up. Can J Urol. 2017 Jun;24(3):88478852 .

24. Ruiter-Ligeti J, Agbo C, Dahan M: The impact of semen processing on sperm parameters and pregnancy rates after intrauterine insemination. Minerva Ginecol. 2017; 69(3):218-224

25. Hassan N, Agbo C, Dahan MH: Pregnancy rates unaffected by sperm count in intrauterine insemination: a retrospective cohort study. Minerva Ginecol. 2017; 69(1):6-12.

26. Punjabi U, De Neubourg D, Van Mulders H, Cassauwers W, Peeters K: Validating semen processing for an intrauterine program should take into consideration the inputs, actions and the outputs of the process.

27. Jansen CHJR, Elisen MGLM, Leenstra CW, Kaaijk EM, van Stralen KJ, Verhoeve HR: Longer time interval between semen processing and intrauterine insemination does not affect pregnancy outcome. Fertil Steril. 2017; 108(5):764-9.
28. Lee J, Hwang S, Lee J, Yoo J, Jang D, Hwang K, Kim M: Effect of insemination timing on pregnancy outcome in association with female age, sperm motility, sperm morphology and sperm concentration in intrauterine insemination. J Obstet Gynaecol Res. 2018; 44(6):1100-1106.

29. Liu WJ, Li WT, Zhang RL, Gao JJ, Wang L, Li YM: Factors influencing the clinical pregnancy rate following intrauterine insemination. Zhonghua Nan Ke Xue. 2015; 21(11):992-6.

30. Zhang K, Shi Y, Wang E, Wang L, Hu Q, Dai Y, Xu $\mathrm{H}$, Zhang J, Jin P, Chen X, Shu J: Ovarian stimulated cycle: not a better alternative for women without ovulation disorder in intrauterine insemination. Oncotarget. 2017; 8(59):100773-80.

31. Huyghe S, Verest A, Thijssen A, Ombelet W: Influence of BMI and smoking on IUI outcome with partner and donor sperm. Facts Views Vis Obgyn. 2017; 9(2):93-100.

32. Na L, Chen Y, Zhai H, Liao A, Huang D: Effects of maternal body mass index on pregnancy outcome after 8570 artificial insemination cycles with donor's sperm. Gynecol Endocrinol. 2018: 1-5. 